\title{
TILTED CAPABLE QUADRUPED SPIDER ROBOT
}

\author{
${ }^{1}$ Kevin Hugo \\ ${ }^{1}$ Program Studi Teknik Informatika Fakultas IImu Komputer, \\ Universitas Katolik Soegijapranata \\ 1'khugo@rocketmail.com
}

\begin{abstract}
Development of an Arduino Spider Robot, or known as Quadruped that could walk on titled grounds. The main purpose is to achieve capability to handle grounds that are tilted on left, right, up, and down tilted. The main parts are SG90 Servos and an Arduino Nano. The Arduino Nano will be the core or brain for the Spider. The way how this spider robot will walk is determined by the algorithm that will be made by the Researcher. The Researcher will start making the spider robot's walking algorithm from scratch. This Spider Robot can be added with extra modules like camera or some other useful modules and can be developed more further to reach some areas unreachable by human.
\end{abstract}

Keywords: Arduino, SG90 Servo, Spider Robot.

\section{Pendahuluan}

Sekarang ini, hampir semua aspek kehidupan kita tidak terlepaskan dengan keberadaan teknologi, Robot adalah salah satu bukti bahwa seberapa jauh perkembangan teknologi sudah maju. Robot memiliki banyak sekali bentuk, seperti hewan, bahkan manusia. Banyak sekali hal yang bisa dilakukan oleh Robot, salah satu yang paling sederhana adalah bergerak bahkan berjalan.

Tidak semua area bisa diakses oleh manusia, seperti kolong kecil, area teradiasi atau beracun [1]. Tempat beradiasi atau beracun adalah area yang sangat berbahaya bila diakses oleh manusia, bahkan dengan baju anti-radiasi sekalipun tetap memiliki resiko [1]. Robot bisa dibuat dengan banyak ukuran. Robot dengan ukuran kecil seperti robot laba-laba, bisa digunakan untuk mengakses area kecil seperti kolong. Selain itu, robot juga kebal terhadap radiasi dan racun.

Berdasarkan dari fakta-fakta tersebut, peneliti memiliki ide untuk mengembangkan robot laba-laba berkaki empat yang bisa berjalan di bidang miring. Dengan robot ini, area tak bisa diakses karena kecilnya atau area berbahaya bisa diakses tanpa ada ancaman terkena radiasi atau racun.

Komponen utama dari robot laba-laba ini adalah arduino nano yang sebagai otak dari robot laba-laba ini. Semua componen akan dikontrol oleh arduino nano. Komponen terpenting kedua adalah SG90 servo, yang akan bekerja sebagai sendi-sendi robot laba-laba yang bisa digerakkan.

Hasil dari project ini adalah untuk membuat robot laba-laba yang bisa berjalan di bidang miring. 4 arah kemiringan utama adalah kanan, kiri, atas, dan bawah. Bidang testing akan berada di papan kayu dan papan akrilik.

\section{LANDASAN TEORI}

Ada beberapa jurnal yang digunakan oleh peneliti sebagai referensi, salah satunya adalah jurnal oleh Álvarez, Rojas \& Rodriguez "Design and Development of a Quadruped Spider Robot" 
[2]. Jurnal ini membahas tentang pengembangan robot berkaki empat. Tujuan utama dari jurnal ini adalah untuk mengetahui bagaimana sebuah robot laba-laba berkaki empat dan binatang berkaki empat berjalan secara matematika. Untuk memenuhi tujuan jurnal, pertama para peneliti belajar bagaimana laba-laba asli berjalan, jadi para peneliti bisa memikirkan bentuk fisik robot laba-laba yang paling cocok. Cara lain para peneliti untuk mencapai tujuannya adalah dengan mengimplementasikan ilmu matematika. Kesamaan antara project ini dengan jurnal referensi ini adalah jumlah kaki, jumlah servo, dan Arduino Nano sebagai pengontrol robot. Robot di jurnal referensi juga memasang 4 servo terdekat dengan badan robot yang bisa bergerak secara horizontal, yang lain nya secara vertical. Walaupun robot jurnal referensi ini mirip dengan robot project ini, perbedaannya adalah bagaimana cara membuat robot ini bisa berjalan. Jika para peneliti robot jurnal referensi ini menggunakan pendekatan secara matematika untuk membuat robot jurnal referensi ini berjalan, peneliti robot project ini tidak menggunakan metode-metode matematika khusus untuk membuat robot berjalan.

Jurnal yang lain adalah jurnal oleh Arun et.al "Arduino Quadruped Robot"[3]. Jurnal ini menunjukan robot berkaki empat, yang dikembangkan di jurnal ini. Robot berkaki empat ini menggunakan arduino nano sebagai otak dari robot berkaki empat tersebut, dan 12 servo sebagai sendi-sendi yang berguna untuk menggerakkan robot. Peneliti jurnal ini pertama mempelajari bagaimana hewan berjalan. Cara jalan tersebut disebut Gait. Persamaan antara jurnal ini dengan project ini adalah sama-sama memakai empat kaki, setiap kaki juga menggunakan servo, yang akhirnya menjadi 12 servo yang akan digunakan. Tetapi, semua servo di robot berkaki empat pada jurnal ini dipasang supaya hanya berotasi secara vertikal sedangkan robot laba-laba pada projectini memiliki 4 servo pada setiap servo yang paling dekat dengan badan utama robot laba-laba yang dipasang supaya berotasi secara horizontal. Selain dari itu, dilihat dari pemasangan servo, robot berkaki empat jurnal ini hanya bisa berjalan maju atau mundur.

Jurnal yang lain adalah jurnal oleh Ho, Choi \& Lee "Development of a Biomimetic Quadruped Robot" [4] menunjukan pengembangan robot biomimetik berkaki empat. Jurnal ini bertujuan untuk pengembangan robot berkaki empat yang mudah. Untuk mencapai kemudahan, para peneliti menggunakan empat kaki dan mengurangi Degrees Of Freedom (DOF) setiap kaki. Selain itu, tidak seperti robot berkaki empat pada umumnya yang menggunakan servo sebagai penggerak, robot jurnal ini menggunakan aktuator sebagai penggerak kaki. Beberapa kemiripan ditemukan dalam jurnal ini dengan project ini, salah satunya adalah jumlah kaki. Jurnal ini menggunakan 4 kaki, tetapi hanya 2 sendi pada setiap kaki, tidak seperti project ini yang menggunakan 3 sendi pada setiap kaki. Selain itu, peneliti project ini tidak akan membuat cara berjalan robotnya mirip dengan robot jurnal ini, karena robot jurnal ini mengangkat 2 kaki yang bersamaan pada saat jalan, sedangkan robot laba-laba project ini tidak bisa berdiri tegak apabila lebih dari satu kaki diangkat.

Jurnal selanjutnya yang berhubungan dengan penelitian ini adalah jurnal oleh Kakarut, Dirdu, Yilmaz "Design of Six Legged Spider Robot and Evolving Walking Algorithms" [5]. Jurnal ini berbicara tentang desain dan pengembangan robot berkaki enam atau yang nama lainnya adalah 
hexapod. Robot berkaki enam ini menggunakan 2 arduino, yang satu sebagai master dan yang satunya dikonfigurasi sebagai slave, dan 18 servo sebagai sendi-sendi untuk menggerakkan setiap kaki robot. Salah satu tujuan jurnal ini adalah membuat robot berkaki enam yang bisa menangani semua bidang. Untuk mencapai itu, salah satu solusi yang diambil oleh peneliti jurnal ini adalah dengan menggunakan 6 kaki yang menggunakan 3 servo pada setiap kaki. Persamaan antara jurnal ini dengan project ini adalah jurnal ini menggunakan arduino dan servo. Tetapi, perbedaannya adalah jumlah arduino dan servo nya. Bila jurnal ini menggunakan 2 arduino dan 18 servo, project ini hanya menggunakan 1 arduino dan 12 servo. Selain itu, robot laba-laba pada project ini juga tidak menggunakan sensor pendeteksi seperti ultrasonic.

Jurnal selanjutnya yang menjadi referensi adalah jurnlah oleh Roy \& Pratihar "Dynamic Modelling and Energy Consumption Analysis of Crab Walking of a Six-legged Robot” [6]. Jurnal ini umumnya berbicara tentang pengembangan robot berkaki enam. Salah satu tujuan utama dari jurnal ini adalah untuk menganalisa konsumsi baterai dalam cara berjalan yang berbeda untuk menemukan cara jalan yang paling hemat baterai. Jurnal ini menggunakan lebih dari satu cara berjalan dan akan dianalisa konsumsi daya nya untuk menemikan cara jalan seperti apa yang menggunakan daya paling sedikit tetapi mampu untuk menyelesaikan hal yang sama cara berjalan lain juga mampu. Jurnal ini dengan project ini sama-sama menggunakan 12 servo, tetapi jumlah kakinya berbeda. Karena jurnal ini menggunakan 6 kaki, tidak memungkinkan untuk mencoba mengimplementasikan cara jalan robot jurnal ini dengan robot project ini.

Jurnal lain yang menjadi referensi adalah jurnal oleh Teymourzadeh et. al. "Adaptive Intelligent Spider Robot" [7]. Jurnal ini menunjukkan robot laba-laba yang dipasang beberapa sensor. Tujuan dari jurnal ini adalah untukmengembangkan robot berkaki empat yang bisa berfungsi tanpa dikte dari manusia. Untuk mencapai tujuan jurnal, para peneliti jurnal menggunakan lebih dari satu sensor, yaitu sensor temperatur, sensor asap, dan sensor ultrasonik. Robot jurnal ini dengan robot project ini menggunakan jumlah servo yang sama, tetapi perbedaannya adalah pada pengontrol robot. Jika robot jurnal ini menggunakan Natual Instrument Board sebagai pengontrol robot, robot project ini menggunakan Arduino Nano sebagai pengontrol robot.

Jurnal yang juga menjadi referensi adalah jurnal oleh Vanhuy et. al. "Simple Robotic Hand in Motion Using Arduino Controlled Servos" [8]. Jurnal ini menunjukan pengembangan robot tangan yang menggunakan sensor kelenturan sebagai pengontrol robot tangan. Tujuan dari jurnal ini adalah untuk membuat alat terapi tangan untuk orang yang memiliki pengurangan fungsi tangan seperti pasien stroke. Para peneliti menggunakan tangan hasil print 3D dan sebuah sarung tangan yang sudah dipasang dengan sensor kelenturan untuk pengembangan dan memenuhi tujuan jurnal. Jurnal ini menggunakan 5 sensor kelenturan yang setiap sensor dipasang di setiap jari sarung tangan dan setiap jari tangan hasil print 3D akan dipasang dengan 5 servo untuk menggerakkan 1 jari, yang totalnya adalah 25 servo untuk 5 jari. Dalam jurnal ini, para peneliti menggunakan metode pemograman yang membuat pergerakan servo lebih lambat tetapi lebih halus. Perbedaan antara 
jurnal ini dengan project ini cukup jauh karena jurnal ini mengembangkan robot tangan, sedangkan project ini mengembangkan robot berkaki empat.

Jurnal terakhir yang menjadi referensi adalah jurnal oleh Waghe, Byohar \& Ghormade "A Real Time Design and Implementation of Walking Quadruped Robot for Enviromental Monitoring" [9]. Jurnal ini membahas pengembangan robot berkaki empat yang dipasang beberapa sensor seperti sensor ultrasonik dan sensor suhu dan kelembapan. Sensor-sensor tersebut digunakan untuk melakukan analisa lingkungan. Hal lain yang menjadi tujuan utama dari jurnal ini adalah mengembangkan robot laba-laba yang bisa berjalan di berbagai bidang. Untuk mencapai tujuan tersebut, para peneliti menggunakan metode yang dinamakan Inverse Kinematic. Inverse Kinematic adalah metode yang terdiri dari rumus matematika yang mempermudah pengembangan algoritma berjalan robot. Ada beberapa persamaan antara robot jurnal ini dengan robot project ini, yaitu jumlah servo, jumlah kaki, dan Arduino sebagai pengontrol robot. Walaupun secara fisik mirip, yang membedakan adalah cara pengembangan algoritma berjalan nya. Jika para peneliti jurnal ini menggunakan metode Inverse Kinematic, peneliti project ini tidak menggunakan metode khusus untuk mengembangkan algoritma berjalan.

\section{Metodologi Penelitian}

\section{Desain dan Skema Robot Laba-laba}

Pertama, dibutuhkan sebuah frame robot laba-laba sebelum semuanya bisa dilaksanakan dan diselesaikan. Peneliti menggunakan frame robot laba-laba yang dicetak menggunakan printer 3D dengan PLA sebagai material untuk frame dan kompatibel dengan servo SG90. Servo SG90 adalah sebuah sebuah controller dengan motor dengan sumbu putar $180^{\circ}$ yang dimana cocok jika diimplementasikan sebagai kaki-kaki dari robot [10]. Pengetesan secara cepat menunjukkan bahwa frame robot laba-laba yang dicetak menggunakan printer 3D yang digunakan untuk penelitian ini adalah frame yang seimbang, karena robot laba-laba ini masih bisa berdiri tegak walaupun salah satu kakinya diangkat dengan catatan tanpa beban. Selain itu, frame robot laba-laba yang dicetak menggunakan printer 3D ini ringan karena materialnya. Berikut adalah gambar yang menunjukan bentuk fisik robot laba-laba:

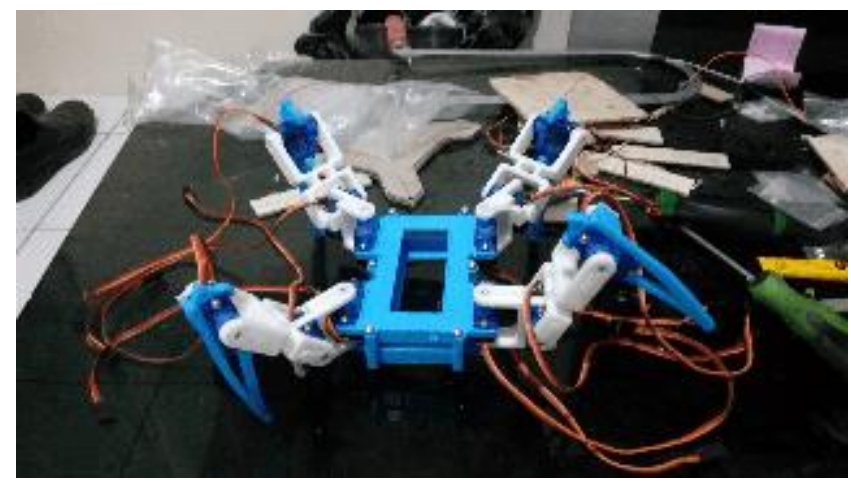

Gambar 1. Robot Laba-laba (Tanpa Beban) 
Selain itu, modul dan alat yang digunakan oleh peneliti dalan penelitian ini adalah arduino nano, arduino nano shield, servo SG90, kabel jumper, step down, adapter $12 \mathrm{~V} 3 \mathrm{~A}$, dan potensiometer.

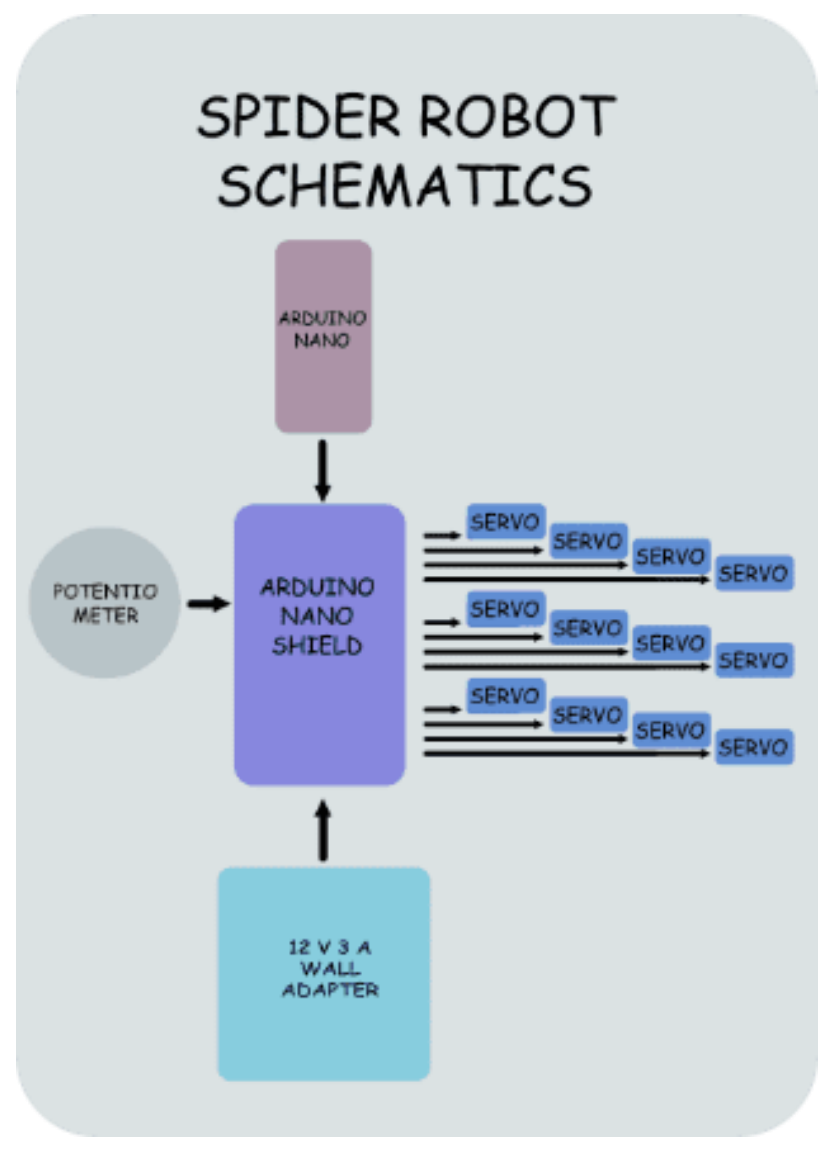

Gambar 2. Skema Robot Laba-laba

Skema diatas menunjukan bahwa modul yang paling sering digunakan adalah servo, karena peneliti menggunakan frame robot laba-laba yang memiliki 12 sendi yang bisa digerakkan, maka dibutuhkan 12 servo supaya semua sendi bisa digerakkan. Servo yang terpasang akan bekerja sebagai sendi yang akan menggerakan semua bagian kaki di robot laba-laba. Arduino nano akan digunakan sebagai otak untuk robot laba-laba. Selain itu, potensiometer akan digunakan sebagai pengontrol pergerakan miring seperti apa yang akan dieksekusi oleh robot laba-laba. Yang terakhir adalah adapter $12 \mathrm{~V} 3 \mathrm{~A}$ yang akan digunakan sebagai sumber daya untuk robot laba-laba. Dilihat dari sumber tenaganya, robot laba-laba ini akan mempunyai batas jarak yang bisa ditempuh karena sumber tenaga yang dipakai memiliki kabel yang membentang dari stopkontak sampai ke robot laba-laba. 

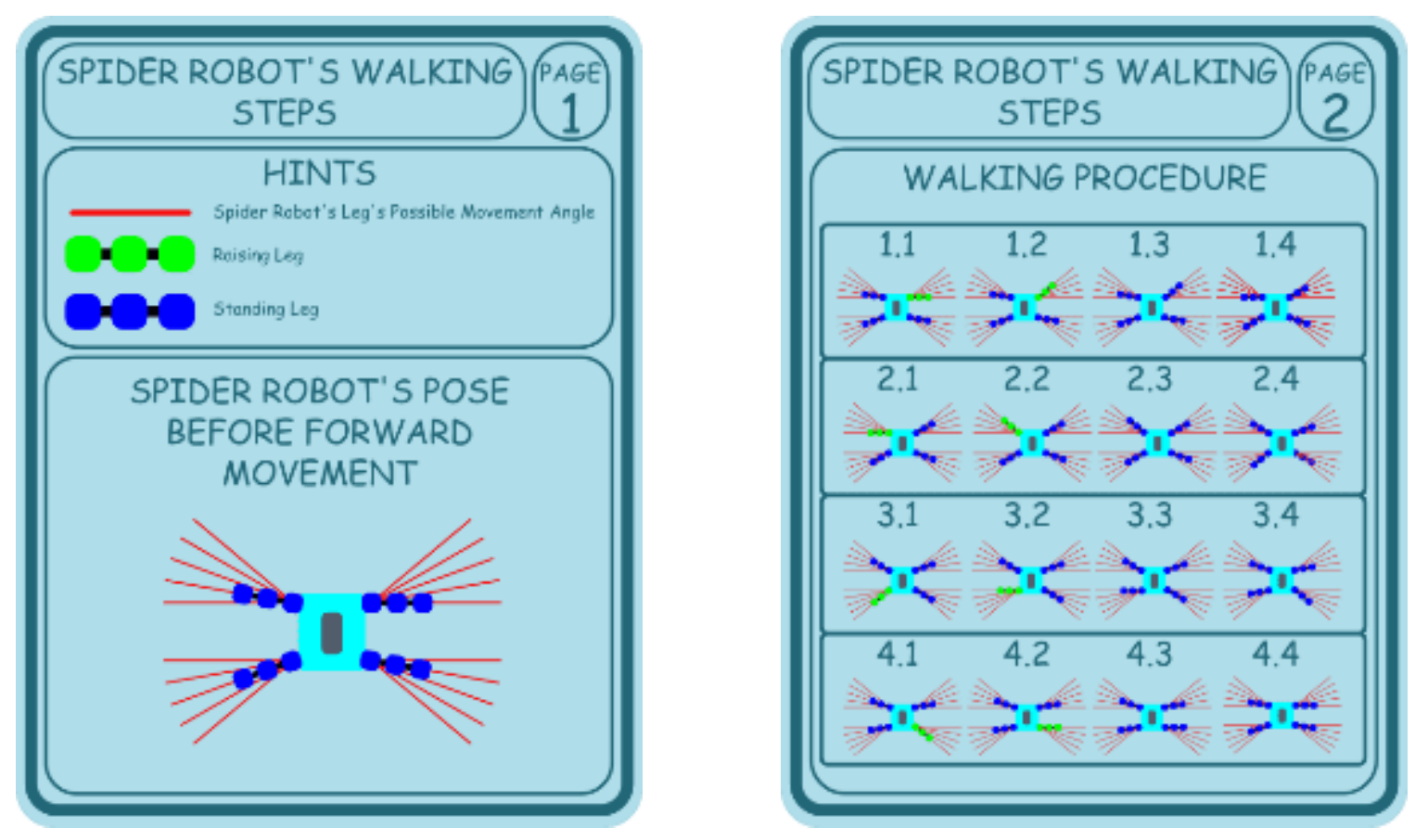

Gambar 3. Prosedur Berjalan Robot Laba-Laba halaman pertama dan kedua

Prosedur berjalan tersebut menunjukkan prosedur bagaimana robot laba-laba akan berjalan. Prosedur berjalan diatas akan menjadi dasar utama bagaimana robot akan berjalan pada bidang datar dan miring. Pergerakan setiap kaki akan mirip pada saat berjalan di bidang datar dan miring seperti yang ditunjukkan pada gambar diatas. Namun, yang membedakan adalah beberapa servo akan diatur rotasinya tergantung dari bidang miring seperti apa yang akan menjadi dasar dimana robot akan berjalan.

\section{Hasil dan Pembahasan}

Pada saat proses pengembangan, peneliti menemukan total 2 algoritma berjalan. Algoritma berjalan kedua adalah algoritma hasil pengembangan dari algoritma pertama. Yang membuat algoritma berjalan pertama dengan algoritma berjalan kedua berbeda adalah kehalusan pergerakan dan kecepatan pergerakan yang bisa diatur lebih baik. Untuk saat ini, algoritma berjalan kedua dikonfigurasi oleh peneliti supaya pergerakannya sedikit lebih lambat daripada algoritma berjalan pertama, dengan tujuan supaya peneliti bisa tahu, apakah pergeratan lebih cepat tetapi tidak halus akan memberikan hasil yang berbeda dibandingkan pergerakan yang lebih lamban tetapi halus. Dibawah ini adalah tabel-tabel yang menunjukkan hasil test algoritma berjalan pertama dan algoritma berjalan kedua di papan kayu. 


\begin{tabular}{l}
\begin{tabular}{|c|c|c|c|c|}
\hline $\begin{array}{c}\text { FIRST WALKING ALGORITHM } \\
\text { SPEED TESTING RESULT }\end{array}$ & \multicolumn{3}{c|}{ WOOD BOARD } \\
\hline Angle Direction & Maximum Angle & Test 1 & Test 2 & Test 3 \\
\hline Left & 16 & $21.87 \mathrm{~s}$ & $21.69 \mathrm{~s}$ & $21.66 \mathrm{~s}$ \\
\hline Right & 16 & $22.69 \mathrm{~s}$ & $20.99 \mathrm{~s}$ & $20.70 \mathrm{~s}$ \\
\hline Up & 12 & $29.62 \mathrm{~s}$ & $30.00 \mathrm{~s}$ & $29.70 \mathrm{~s}$ \\
\hline Down & 22 & $10.50 \mathrm{~s}$ & $10.09 \mathrm{~s}$ & $10.66 \mathrm{~s}$ \\
\hline NOTE : & $\begin{array}{l}\text { - Maximum Angle's value is in degree } \\
\text { - The start and finish's distance is about } 15 \mathrm{~cm}\end{array}$ \\
\hline
\end{tabular} \\
\hline
\end{tabular}

\begin{tabular}{|c|c|c|c|c|}
\hline \multicolumn{5}{|c|}{$\begin{array}{l}\text { FIRST WALKING ALGORITHM } \\
\text { SPEED TESTING RESULT } \\
\end{array}$} \\
\hline Angle Direction & Maximum Angle & Test 1 & Test 2 & Test 3 \\
\hline Left & 16 & $21,87 \mathrm{~s}$ & $21.69 \mathrm{~s}$ & $21,66 \mathrm{~s}$ \\
\hline Right & 16 & $22.69 \mathrm{~s}$ & $20.99 \mathrm{~s}$ & $20.70 \mathrm{~s}$ \\
\hline$u_{p}$ & 12 & $29.62 \mathrm{~s}$ & $30.00 \mathrm{~s}$ & $29.70 \mathrm{~s}$ \\
\hline Down & 22 & $10.50 \mathrm{~s}$ & $10.09 \mathrm{~s}$ & $10.66 \mathrm{~s}$ \\
\hline \multicolumn{5}{|c|}{$\begin{array}{l}\text { Maximum Angle's value is in degree } \\
\text { - The start and finish's distance is about } 15 \mathrm{~cm} \\
\text { - Spider Robot slip for about } 5 \mathrm{~cm} \text { on left and right anqle }\end{array}$} \\
\hline
\end{tabular}

Gambar 4. Hasil Test Algoritma Berjalan Pertama di Papan Kayu

Dibawah ini adalah hasil test algoritma berjalan bertama dan algoritma berjalan kedua di papan akrilik.

\begin{tabular}{l}
\begin{tabular}{|c|c|c|c|c|}
\hline $\begin{array}{c}\text { FIRST WALKING ALGORITHM } \\
\text { SPEED TESTING RESULT }\end{array}$ & \multicolumn{3}{|c|}{ ACRYLIC BOARD } \\
\hline Angle Direction & Maximum Angle & Test 1 & Test 2 & Test 3 \\
\hline Left & 16 & $18.54 \mathrm{~s}$ & $18.45 \mathrm{~s}$ & $17.88 \mathrm{~s}$ \\
\hline Right & 16 & $17.43 \mathrm{~s}$ & $18.15 \mathrm{~s}$ & $17.93 \mathrm{~s}$ \\
\hline Up & 12 & $29.77 \mathrm{~s}$ & $29.71 \mathrm{~s}$ & $29.54 \mathrm{~s}$ \\
\hline Down & 24 & $07.57 \mathrm{~s}$ & $07.41 \mathrm{~s}$ & $07.65 \mathrm{~s}$ \\
\hline NOTE: - Maximum Angle's value is in degree \\
\hline
\end{tabular} \\
\hline
\end{tabular}

\begin{tabular}{|c|c|c|c|c|}
\hline \multicolumn{5}{|c|}{$\begin{array}{c}\text { SECOND WALKING ALGORITHM } \\
\text { SPEED TESTING RESULT }\end{array}$} \\
\hline Angle Direction & Maximum Angle & Test 1 & Test 2 & Test 3 \\
\hline Left & 12 & $21,34 s$ & $21.63 \mathrm{~s}$ & $20.51 s$ \\
\hline Right & 12 & $24.43 \mathrm{~s}$ & $23.51 \mathrm{~s}$ & $23.69 \mathrm{~s}$ \\
\hline$u_{p}$ & 14 & 51.835 & $52.88 \mathrm{~s}$ & $51.81 \mathrm{~s}$ \\
\hline Down & 26 & 09.885 & $09.66 \mathrm{~s}$ & $09.93 \mathrm{~s}$ \\
\hline \multicolumn{5}{|c|}{$\begin{array}{l}\text { - Maximum Angle's value is in degree } \\
\text { - The start and finish's distance is about } 15 \mathrm{~cm} \\
\text { - Spider Robot slip for about } 8 \mathrm{~cm} \text { on left and right angle }\end{array}$} \\
\hline
\end{tabular}

Gambar 5. Hasil Test Algoritma Berjalan Pertama di Papan Akrilik

Karena setiap algoritma berjalan memiliki kemampuan maksimal sendiri-sendiri yaitu kemampuan derajat kemiringan dan kecepatan, peneliti harus memberi lintasan yang adil yang mampu dilalui oleh setiap algoritma berjalan. Adil yang dimaksut adalah seperti sama-sama mengetest algoritma berjalan pertama dan algoritma berjalan kedua di papan kayu dengan kemiringan yang sama. Dibawah ini adalah tabel-tabel yang menunjukan perbandingan yang adil antara algoritma berjalan pertama dengan algoritma berjalan kedua di papan kayu dan papan akrilik. Yang dibandingkan adalah kemiringan maksimal dan kecepatan di kemiringan yang adil. 

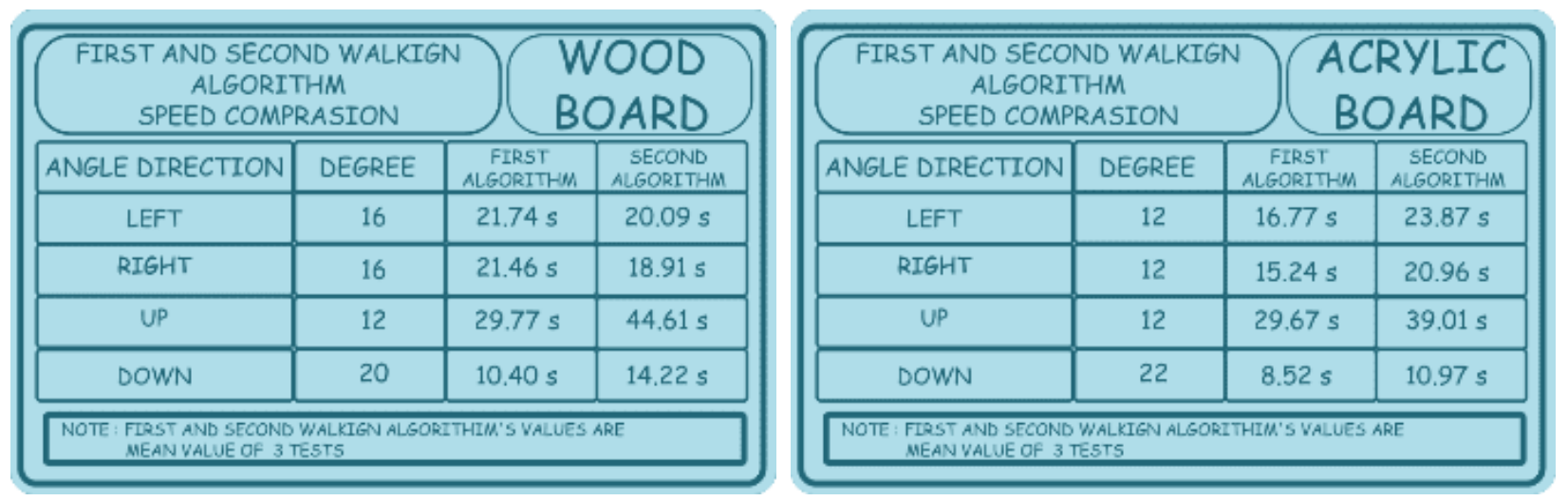

Gambar 6. Perbandingan Kecepatan Maksimal di Papan Kayu (atas) dan di Papan Akrilik (bawah)

Algoritma berjalan pertama dengan algoritma berjalan kedua memiliki kemampuannya masing-masing, kelebihan dan kelemahan di setiap bidang, kayu maupun akrilik. Seperti algoritma berjalan pertama, secara keseluruhan algoritma berjalan pertama bisa bekerja lebih baik di papan kayu, terutama bisa menghandel 2 derajat lebih untuk arah kemiringan keatas. Tidak seperti algoritma berjalan pertama, algoritma berjalan kedua secara umum bekerja lebih buruk pada papan akrilik, terutama hanya bisa menghandel 4 derajat kurang daripada di papan kayu, tetapi bisa menghandel 2 derajat lebih untuk kemiringan kearah atas dan 4 derajat lebih untuk kemiringan kearah bawah, dan bisa berjalan lebih cepat untuk kemiringan kearah bawah pada papan akrilik.

\section{KESIMPULAN}

Setelah penliti selesai melakukan testing dan tujuan utama penelitian sudah tercapai, peneliti menemukan beberapa kesimpulan. Kesimpulan pertama adalah alas kaki robot yang berbahan PLA harus diberi lapisan yang kasar supaya kaki robot tidak licin jika hanya mengandalkan kaki robot tanpa alas yang dilapisi. Kesimpulan kedua adalah bahwa pergerakan yang cepat belum tentu berarti berjalan lebih cepat, terutama di bidang miring. Kesimpulan ketiga adalah algoritma berjalan memiliki peran yang penting untuk kemampuan robot dalam menghandel bidang miring. Kesimpulan keempat adalah desain fisik dan material robot juga memiliki peran penting. Kesimpulan kelima adalah hanya dengan memodifikasi servo dengan nilai yang konstan untuk menghandel bidang miring tidaklah cukup. Kesimpulan yang terakhir adalah bidang yang menjadi pijakan dimana robot akan berjalan juga akan menjadi penentu apakah algoritma berjalan akan sukses atau gagal.

\section{Daftar Pustaka}

[1] A. Razak et al., "Development of mobile robot in confined space application," Mar. 2017, pp. 190-195. doi: 10.1109/CSPA.2017.8064949.

[2] S. N. Álvarez, M. C. Rojas, and H. León-Rodriguez, "Design and development of a quadruped spider robot," 2018.

[3] V. Arun, V. S. Prasad, G. Sridhar Reddy, L. Ruthwik Reddy, M. Venkatesh, and M. Sai Pavan Kumar, "Arduino Quadruped Robot," IOSR-JECE, vol. 11, no. 3, pp. 44-50. 
[4] T. Ho, S. Choi, and S. Lee, "Development of a Biomimetic Quadruped Robot," Journal of Bionic Engineering, vol. 4, no. 4, pp. 193-199, Dec. 2007, doi: 10.1016/S16726529(07)60032-8.

[5] T. Karakurt, A. Durdu, and N. Y1lmaz, "Design of Six Legged Spider Robot and Evolving Walking Algorithms," International Journal of Machine Learning and Computing, vol. 5, pp. 96-100, Apr. 2015, doi: 10.7763/IJMLC.2015.V5.490.

[6] S. S. Roy and D. K. Pratihar, "Dynamic modeling and energy consumption analysis of crab walking of a six-legged robot," in 2011 IEEE Conference on Technologies for Practical Robot Applications, Apr. 2011, pp. 82-87. doi: 10.1109/TEPRA.2011.5753486.

[7] R. Teymourzadeh, R. N. Mahal, N. K. Shen, and K. W. Chan, "Adaptive intelligent spider robot," in 2013 IEEE Conference on Systems, Process Control (ICSPC), Dec. 2013, pp. 310315. doi: 10.1109/SPC.2013.6735153.

[8] T. Vanhuy, D. Minh, K. Nguyen Phan, and V. Tran, "Simple Robotic Hand in Motion Using Arduino Controlled Servos," International Journal of Science and Research (IJSR), vol. 6, pp. 6-391, Mar. 2017, doi: 10.21275/ART20171455.

[9] R. G. Waghe, D. Bhoyar, and S. Ghormade, "A Real Time Design and Implementation of Walking Quadruped Robot for Environmental Monitoring," IRJET, vol. 05, no. 05, p. 8.

[10] “SERVO MOTOR SG90 DATA SHEET,” p. 1. 